\title{
EAR FoREIGN BODIES: OBSERVATIONS ON THE Clinical Profile in Sokoto, Nigeria
}

\author{
K. R. Iseh and M. Yahaya
}

Department Of Ear, Nose and Throat, Usmanu Danfodiyo University Teaching Hospital, Sokoto, Nigeria Reprint Requests To: Dr. K. R. Iseh, Department of E.N.T, Usmanu Danfodiyo University Teaching Hospital, Sokoto, Nigeria. E-mail: frobih@yahoo.com

\begin{abstract}
Background/objectives: Ear foreign bodies are common otorhinolaryngological emergencies which must be removed otherwise they may present with various complications. This paper reviews cases of ear foreign bodies seen over a seven year period from January 1995 to December 2001 in the Ear, Nose and Throat (ENT) department of Usmanu Danfodiyo University Teaching Hospital Sokoto, Nigeria.

Method: This is a retrospective study of all case folders of patients who presented with ear foreign bodies whose clinical features and management modalities were analyzed .

Results: The total number of patients reviewed were 207.There were 126males (60\%) and 81 females (40\%) with a male to female ratio of 1.5:1.Their ages ranged from 1 to 65years with $61.8 \%$ being children under 10years old. Agricultural seed was the commonest documented foreign body (15\%). Deliberate insertion by patients accounted for $70 \%$ of the cases while accidental insertion accounted for $30 \%$. Ear foreign bodies became complicated in 41 patients (19.8\%) at presentation one of them requiring a major surgical operation (posterior tympanotomy) to remove the foreign body. About $99.5 \%$ of the foreign bodies were removed through the per meatal approach with $79.8 \%$ being carried out by the nurses and doctors who had received basic training to do so.

Conclusion: Ear foreign bodies may become complicated and so needs to be removed using standard methods which should be carried out by those specially trained to do so.
\end{abstract}

Key words: Ear foreign bodies, clinical profile, Nigeria

\footnotetext{
Résumé

Introduction/Objectif: Des corps étrangers dans l'oreille sont des situations fréquents d'oto-rhinolaryngologie d'urgence qui doivent être enlevés sinon, ils peuvent présenter des complications divers. Ce document passe en revue les cas des corps étrangers d'oreille vus pendant une durée de sept ans allant de janvier 1995 au décembre 2001, dans le Département du nez, de l'oreille, et de la gorge (ONG) Centre hospitalier Universitaire dù Usman Danfodiyo, Sokoto, Nigeria.

Méthode: II s'agit d'une étude rétrospective des dossiers de tous les cas de patients qui ont présenté des corps étrangers de l'oreille dont les caractéristiques cliniques et les modalités de gestion ont été analysés.

Résultats: Le nombre total de 207 patients ont été examinés. Il y avait 126 hommes soit 60\% et 81 du sexe féminin soit $40 \%$ avec une proportion hommes / femmes de 1:5:1. Leur âge varie entre 1 à 65 ans avec $61,8 \%$ étant des enfants âgés de moins de 10 ans. De semences agricoles a été le corps étranger la plus fréquente (15\%). D'insertion délibérée par les patients représentaient $70 \%$ des cas, alors que l'insertion accidentelle représentaient 30\%. Corps étrangers de l'oreille est devenue compliquée chez 41 des patients soit $19,8 \%$, pendant présentation et un patient nécessitant une opération chirurgicale importante (postérieur tympanotomie) afin d'enlever le corps étranger. Environ 99,5\% des corps étrangers ont été enlevés par le biais de l'approche par meatal avec $79,8 \%$ réalisés par les infirmières et les médecins qui ont reçu une formation de base pour cette opération.
} 
Conclusion: Les corps étrangers de l'oreille peuvent devenir complique et doit être enlevé en utilisant des méthodes standard qui doivent être menées par ceux spécialement formés pour cette opération.

Mots clés: Corps étrangers de l’oreille, profil clinique Nigeria

\section{Introduction}

Ear foreign bodies (EFB) could be described as any object other than wax or cerumen that is foreign to the ear. They could be either animate or inanimate objects. $^{1-4}$ Ear foreign bodies (EFB) are common daily problems all over the world and is the commonest emergency in the Ear, Nose and Throat (ENT) departments in Nigeria particularly in children. ${ }^{5-9}$ Certain conditions have been identified leading to foreign body insertion in the ear such as curiosity or desire to explore orifices, imitation, boredom, fun making, mental retardation, insanity among others. ${ }^{1-}$ ${ }^{8}$ Ear foreign body insertion in children also depends on the availability of the objects and absence or presence of watchful caretakers. ${ }^{8}$ Insertion of EFB could be deliberate or accidental from several causes including road traffic or missile injuries to the ear. ${ }^{1-11}$

The external auditory canal (EAC) is the most common area where EFB are usually impacted followed by the middle ear and the inner ear., ${ }^{1,9-11}$ Patients with ear foreign bodies need proper clinical assessment using the headlight or otoscope. Removal of such foreign bodies requires knowledge of certain skills and techniques depending on its location whether in the external auditory canal, the middle ear or the inner ear.

Difficulty at removal especially by untrained or unqualified personnel or with inappropriate instruments usually results in trauma to the EAC or impaction within the middle ear cavity when such foreign bodies are inadvertently pushed farther while trying to remove them. Sometimes they are impacted abinitio from penetrating trauma or missile injuries. ${ }^{10-12}$ This may result in varying degrees of deafness.

Impacted foreign bodies within the middle ear may cause otitis media which can spread to the mastoids and the nasopharynx. When the inner ear is involved, the clinical scenario of symptoms such as vertigo, nausea, vomiting, deafness, cerebrospinal fluid otorrhoea may become more pronounced.

This report from Sokoto, in northwestern Nigeria tries to compare with reports on this subject from other parts of the world. Ear foreign bodies become complicated when wrong methods are used to remove them or as a result of penetrating injuries. Patients may present with or without these complications. Penetrating ear foreign bodies are associated with complications at onset with or without attempted removal.

In sub-Saharan West Africa, dearth of specialists in every specialty of medicine especially in Ear, Nose and Throat (ENT) means that in emergencies such as ear foreign bodies, removal is usually attempted by individuals who do not have sufficient skill or experience to handle such cases. Inappropriate instruments are used which is usually fraught with complications. Most of these cases do not get to the ENT department of most tertiary health institutions` which our center is one of them.

The cases reported here are the ones documented in the department when there was no steady supervising ENT consultant except on part time basis..In the absence of a supervising consultant, documentation in the case folders is usually inadequate and incomplete. So also are the methods of removal of the ETB. It is our desire to present this seemingly common problem in otorhinolaryngology as a source of preventable complications which is discussed in this paper in a developing nation like Nigeria which is often overlooked.

\section{Patients and Methods}

This is a retrospective study of all clinical records of patients who presented to the Ear, Nose, and Throat Department (ENT) of Usmanu Danfodiyo University Teaching Hospital Sokoto, with diagnosis of foreign body in the ear from January 1995 to December 2001. The clinical features and management modalities of these patients documented were analyzed for age, sex, type of foreign body, clinical features, complications, and treatment modalities.

Radiological examination (Towne's view)of mastoids was done only in 3 cases of failed attempt at removal prior to presentation which was complicated by foreign body being pushed further into the EAC or middle ear cavity.

Hearing assessment was not routinely carried out on all patients reviewed with EFB. Deafness was documented as part of the complication in any patient who during the incidence and after the removal of EFB, experienced significant hearing deficit when compared to the pre-injury state based on complaint of the patient and live voice tests carried out by different examiners using whisper, normal conversation, loud voice at $2 \mathrm{ft}(60 \mathrm{~cm})$ ,6inches $(15 \mathrm{~cm})$ away from the ear and at ear level. Such patients required further audiometric assessment but they did not bother to show up after the foreign body was removed.There was no evidence in the case folders that Pure tone Audiometry (PTA) was carried out on any patient before and after the removal of any foreign body. 
Incomplete information (regarding names of foreign body, duration of foreign body impaction, lack of pure tone audiograms and methods of foreign body removal) was a limitation in this study.

\section{Results}

The total number of cases reviewed was 207 . There were 126 males (60\%) and 81 females (40\%) with male to female ratio of $1.5: 1$. The age range was 1 to 65 years. Majority of the cases were children below ten years of age $(61.8 \%)$ with $1-5$ years age range constituting $42 \%, 6-10$ years age range $19.3 \%$ and 11 15 years age range $11.1 \%$ as shown in table 1 .

Deliberate insertion of ear foreign body occurred in $70 \%$ of cases while $30 \%$ of these cases were accidental. The various types of foreign bodies inserted are shown in table 2. Agricultural seed was the commonest documented ear foreign body (15\%). The names of foreign bodies removed were not documented in 93 cases (44.9\%) .

Foreign body in the ear (58\%) followed by pain in the ear (24.2\%) and hearing loss (6.2\%) were the commonest presenting symptoms as shown in table 3 .

Table 1. Age range of patients with ear foreign bodies in Sokoto,, Nigeria

\begin{tabular}{ll}
\hline Age (years) & No. $(\%)$ \\
\hline $0-5$ & $88(42.5)$ \\
$6-10$ & $40(19.3)$ \\
$11-15$ & $23(11.3)$ \\
$16-20$ & $11(5.3)$ \\
$21-25$ & $11(5.3)$ \\
$26-30$ & $16(7.8)$ \\
$31-35$ & $5(2.4)$ \\
$36-40$ & $2(1)$. \\
$41-45$ & $2(1.0)$ \\
$46-50$ & $2(1.0)$ \\
$51-55$ & - \\
$56-60$ & $1(0.5)$ \\
$>60$ & $1(0.5)$ \\
Unknown & $5(2.3)$ \\
\hline Total & $207(100)$ \\
\hline
\end{tabular}

Significant ear trauma to the external auditory meatus(contusion, laceration) and tympanic membrane perforation complicated failed attempted removal before presentation in 41 patients (20.2\%).

Conductive deafness was documented in the affected ears after the removal of ear foreign bodies based only on live voice tests compared with the unaffected ears of 30 patients $(14.5 \%)$ who had traumatic perforation of the tympanic membrane ( 27 patients),and acute suppurative otitis media (3 patients) out of the 41 complicated cases as shown in table 4 who did not have audiometric values from pure tone audiometry to verify these claims.

Table 2. Types of ear foreign bodies in 207 patients

\begin{tabular}{ll}
\hline Type of foreign body & No. (\%) \\
\hline Not specified & $93(44.9)$ \\
Seed (Agricultural) & $31(15.0)$ \\
Dead insects & $14(6.7)$ \\
Stone & $12(5.8)$ \\
Match stick & $11(5.3)$ \\
Bead & $10(4.7)$ \\
Cotton/cotton bud & $9(4.3)$ \\
Animal furs & $8(3.9)$ \\
Pieces of paper & $6(2.9)$ \\
Native medicine & $2(1.0)$ \\
Head of biro & $1(0.5)$ \\
Sand & $1(0.5)$ \\
Flower & $1(0.5)$ \\
Red object (plastic) & $1(0.5)$ \\
Metallic bell & $1(0.5)$ \\
Pieces of balloon & $1(0.5)$ \\
Pencil duster & $1(0.5)$ \\
Glass & $1(0.5)$ \\
Feathers (chicken) & $1(0.5)$ \\
Pieces of kola nut & $1(0.5)$ \\
Chalk & $1(0.5)$ \\
\hline Total & $207(100)$ \\
\hline
\end{tabular}

Table 3. Presenting symptoms of ear foreign bodies in 207 patients

\begin{tabular}{ll}
\hline Symptom & No. (\%) \\
\hline Foreign body in the ear & $120(58)$ \\
Ear ache & $5024.2)$ \\
Hearing loss & $13(6.2$ \\
Ear bleeding & $10(4.8)$ \\
Ear discharge & $8(3.8)$ \\
Noise in the ear & $2(1.0)$ \\
Fever & $1(0.5)$ \\
Itching ear & $1(0.5)$ \\
Headache & $1(0.5)$ \\
Inability to speak & $1(0.5)$ \\
\hline Some patients had combination of symptoms &
\end{tabular}

Simple and straight forward cases of ear foreign bodies were removed by nurses and junior resident doctors(79.8\%) who had received basic training from an ENT surgeon. Complicated or difficult cases were reserved for the senior resident or consultant.

About $99.5 \%$ of the foreign bodies were removed using aural crocodile forceps, ear hook, Jobson Horne's probe, and ear syringing in cases of non vegetative foreign bodies through the per meatal approach. 
Some children required minimal sedation with ketamine to ease the removal of foreign body that were not cooperative. Traumatised EAC had local ear treatment with antibiotic/steroid preparations.

One adult female patient $(0.5 \%)$ with complicated EFB had posterior tympanotomy for the removal of foreign body under general anesthesia when all efforts to remove the rounded metallic boris failed through the per meatal approach (Figure 1).

Table 4. Complications of ear foreign bodies in 207 patients

\begin{tabular}{ll}
\hline Complication & No. (\%) \\
\hline Tympanic membrane perforation & $20(9.7)$ \\
$\begin{array}{l}\text { Trauma to external auditory } \\
\text { canal/bleeding }\end{array}$ & $11(5.3)$ \\
Suppurative otitis media & $7(3.4$ \\
Impaction in the middle ear cavity & $3(1.4)$ \\
\hline Total & $41(19.8)$ \\
\hline
\end{tabular}

Figure 1. Radiograph showing impacted metal (rounded opacity) in the right middle ear cavity

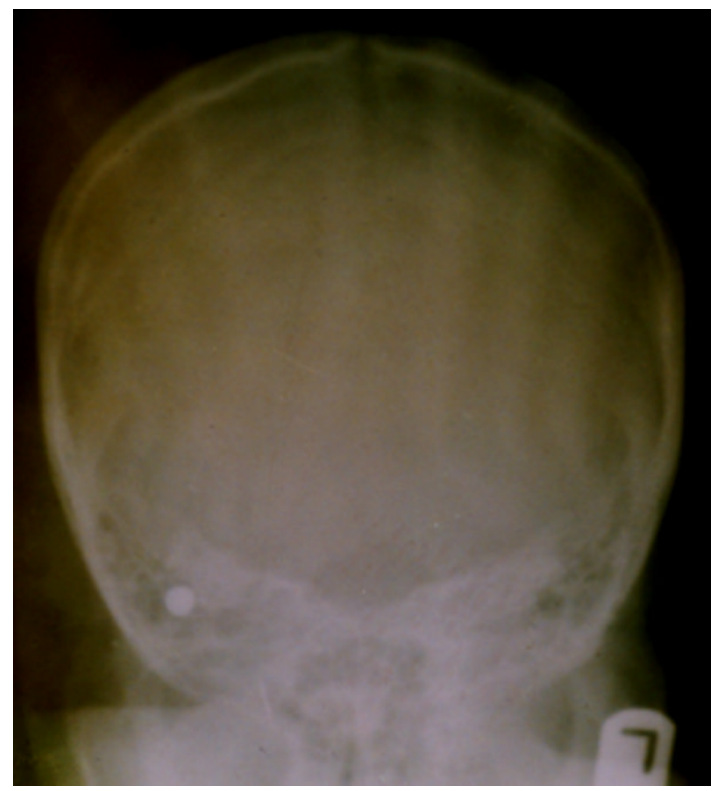

\section{Discussion}

Ear Foreign bodies are common otorhinolaryngological emergencies in most Otorhinolaryngological clinics in Nigeria a subSaharan nation in West Africa and is a common daily problem all over the world. ${ }^{5-10}$ It accounts for about $65.6 \%$ of all otorhinolaryngological emergencies in Usmanu Danfodiyo University Teaching Hospital Sokoto, in Nigeria. It occurred more in children between the ages of 1 and 10 years (61.8\%) with 1-5 years age range(42.5\%) having the largest number. This is a similar finding by many authors who report that it is a disease of children. ${ }^{1-5}$ Although EFB occurs predominantly in children, approximately $27.1 \%$ of the patients in this study were adults who were over $15 y e a r s$ old without any underlying psychiatric disorder one of whom required a major surgery (posterior tympanotomy) to remove the foreign body (Figure 1).

Children commonly play and try to explore body orifices out of curiosity. Therefore the need to watch children carefully and do periodic ear examination in order to detect presence of ear foreign bodies cannot be overemphasized especially when most families in sub-Saharan Africa leave their children under the care of extended families. Such families allow free interaction with several children who play all sorts of games and may partly account for the reason that $70 \%$ of the cases in this study occurred as a result of deliberate insertion.

Ear foreign body such as button battery which have alkaline substance when dissolved causes liquefactive necrosis and if left undetected could cause otitis externa, meatal stenosis, otitis media, facial nerve paralysis and deafness with attendant problems. ${ }^{13}$ Such foreign bodies need to be removed as a matter of urgency. No button batteries were recorded in this report. The names of most of the foreign bodies were not documented in 93cases (44.9\%) apparently because of the ease at which they were removed by the nurses and the resident doctors and lack of understanding of the need for proper documentation in medical record keeping. ${ }^{14}$ However the most commonly documented foreign body was agricultural seed (15\%) which was usually a bit difficult to remove if they were initially syringed causing the seed to swell and become more impacted within the canal.

Most records of patients were incomplete. Record keeping of names of foreign bodies is important and how they are removed. It helps to plan on both preventive and intervention measures. However types of foreign bodies vary from different reports from different parts of the world even though almost every conceivable object has been known to be inserted in the ear. ${ }^{1-13}$ There was male preponderance in this study which is similar with other reports but differs from others which show no sex difference. ${ }^{1-8}$

Successful removal of foreign bodies through the per meatal approach occurred in $99.5 \%$ of the cases with $79.8 \%$ being carried out by nurses and resident doctors in the department. The 41 patients(19.8\%) who came with complications were treated with parenteral antibiotics and local ear treatment for the edema to resolve before the removal of the ear foreign body was carried out. One patient underwent posterior tympanotomy to remove the foreign body under general anesthesia. Those who had perforated tympanic membranes (14.5\%) from trauma(20 cases) or suppuratve otitis media (7cases) or impaction in 
the middle ear ( 3 cases) as a result of failed attempt at removal prior to visiting the clinic had deafness after the extraction of foreign body, significant enough to affect their day to day duties. Although objective hearing assessment was not done in these patients, the harm caused by these untrained personnel were preventable.

There was no mortality recorded despite these complications. Objective hearing assessment would have shown the degree and pattern of hearing loss. It is also important for medico-legal reasons in cases of litigation. It is therefore unfortunate that some patients presenting with ear foreign bodies could end up becoming deaf in the society which is preventable if untrained personnel continue to make attempts to remove ear foreign bodies. This is likely to affect the quality of life of these patients particularly children whose learning capabilities may be impaired in a region where there are no sufficient resources to cope with handicapped children and address their problems. Under this circumstance, a deaf child will end up becoming a liability to the family or society . Management of deafness as a result of tympanic membrane perforation with or without ossicular chain disruption or destruction is far more complex and expensive to handle with variable results.

Standard methods are available for removal of ear foreign bodies which are taught and carried out in centers with competent emergency physicians and or ENT surgeons such as: 1)Ear syringing of nonvegetative objects. 2) Removal with crocodile forceps, ear hooks, or adhesive materials. 3) Surgery when EFB is deep within the middle or inner ear. Trial and error in this area should be avoided.

From our study $79.8 \%$ of the ear foreign bodies were removed by non ENT Specialists. While it may be true that it might be impossible for all ear foreign bodies to be removed by the ENT specialist, ${ }^{15}$ the outcome is usually better with those who have had basic training to do so. This basic training is now available in various Otorhinolaryngological departments of Health institutions and the National Ear care center in Nigeria in order to prevent complications in handling minor ENT ailments when the specialist is not available.

Radiological investigation of the mastoids(Towne's View) was carried out in 3 patients with suspected impaction in the middle ear. Two of these patients had successful removal through the per meatal approach while one required a posterior tympanotomy to remove the impacted metallic boris. A computerized tomographic(CT) scan is superior to conventional x-rays and will usually show more details. This must not necessarily be carried out before surgical extraction except in selected cases with suspected intracranial involvement such as may occur in missile injuries.

Every case of EFB should be treated on its on merit. Methods of foreign body removal vary with the types of foreign bodies. Live insects must be killed first by drowning with oily solutions such as olive oil, petroleum jelly such as liquid paraffin before removal. ${ }^{16}$ Vegetative foreign bodies must not be syringed otherwise they will swell and become more impacted causing more pains and discomfort. This was common with agricultural seed in this study. Cooperation of the patient is vital for effective removal in addition to the availability of relevant forceps and adequate illumination. Some form of restraint may be necessary requiring sedation or general anesthesia. Sedation was used in some children before successful atraumatic removal was possible while one case required general anesthesia.

In sub-Saharan Africa, emergencies arising from ear foreign bodies will continue to pose challenges in management and needs regular appraisal to stem any negative trends associated with its management.

\section{Recommendations}

1. Proper and adequate documentation of cases of ear foreign bodies in centers which handle them. This will enable adequate data to be collated .

2. Parents, relatives and untrained health workers should desist from removing ear foreign bodies.

3. Health workers who will handle ear foreign bodies should be well trained and should know their limits when trying to remove them.

4. Use of traditional medicine in the ear should be discouraged unless their usefulness is scientifically established. This is a common practice in sub- Saharan Africa.

5. Ear foreign body removal except when causing distressing symptoms is not an emergency and so no hasty attempts should be made to remove them. It should be done when the child is cooperative, adequately restrained or under general anesthesia

6. Audiograms are necessary to confirm degree and severity of hearing loss in complicated cases. This requires functional audiometers to do pure tone audiometry.

7. Patients should be educated on the need for follow up out patient visits. The excitement surrounding the removal of ear foreign bodies overwhelms the patient and relatives and do not consider coming back to the hospital necessary as long as the primary problem which brought them to the hospital has been solved.

8. Need for public awareness of the problem of EFB and to ensure that preventive measures are taken by those who have and look after children.

\section{Conclusion}

Ear foreign bodies vary in types and clinical presentations. Complications arising from EFB also vary and need to be managed based on individual merit.

The complications documented in this study 
Were the result of attempts at removal by unqualified personnel which were preventable. Because complications occurred in 41(20.2\%) patients prior to presentation, it is not advisable for individuals to embark on foreign body removal if there is no proper training or adequate facilities to do so in sub-Saharan Africa.

\section{References}

1. Walby AP. Foreign bodies in the ear or nose. In: kerr AG, Adams DA, Cinnamond MJ(eds). ScottBrown's Otolaryngology Pediatric Otolaryngology 6th edition: Butterworth-Heinemann, Oxford, 1997 6/14/1-3.

2. Wright A. Diseases of the external ear. In: Kerr AG, Booth JB(eds). Scott-Brown's Otolaryngology-Otology. ButterworthHeinemann, Oxford, 1997 3/6/11-12.

3. Parisier SC. Injuries of the ear and temporal bone. In: Bluestone CD, Stool SE Scheetz $\mathrm{MD}$ (Eds).Pediatric otolaryngology. Saunders, Philadelphia, 1990;578-9.

4. Bressler K, Shelton C. Ear foreign body removal. A review of 98 consecutive cases. Laryngoscope. 1993;103:367-370.

5. Stuart F, Gabor D, Kerth T. Foreign body of the external auditory canal. Emerg Med Clin North Am. 1987;5:183-189.

6. Das SK. Aetiological evaluation of foreign bodies in the ear and nose. J Laryngol Otol. 1984;98:989-991.

7. Okafor BC. Trauma to ear including foreign bodies. Nigerian Medical Journal. 1983;13:81-86.

8. Ijaduola GTA, Okeowo PA. Foreign body in the ear and its importance; the Nigerian experience. J Trop Pediatr. 1986;32:4-6.

9. Ladapo AA. Danger of foreign bodies in the ear. Niger Med J. 1979;9:120-122.

10. Iseh KR. Impacted ear foreign body - a public health concern. Sahel Medical Journal (Nigeria). 2002;5:160-161.

11. Takoudes TG, Selesnick SH, Lam SM. Transtympanic penetrating injury to the internal auditory canal. Ann Otol Rhinol Laryngol. 2001;110:696-699.

12. Skinner DW, Chui P. The hazard of button-sized batteries as foreign bodies in the nose and ear. J Laryngol Otol. 1986;100:1315-1319.

13. Ameh EA, Shehu BB. Medical record keeping and information retrieval in developing countries: surgeon's perspective. Trop Doct. 2002;32:232234.

14. Ezechukwu CC, Nwawolo CC. Removal of ear and nasal foreign bodies where there is no otorhinolaryngologist. Trop Doct. 2005; 35:1213.

15. O'Toole K, Paris PM, Stewart RD, Martinez R. Removing cockroaches from the auditory canal: controlled trial. N Engl J Med. 1985;312:1197. 